\title{
EDITORAL: O CHEIO E O VAZIO DURANTE A PANDEMIA
}

\section{Maíra Bonafé Sei \\ Universidade Estadual de Londrina \\ Patrícia Silva Lúcio \\ Universidade Estadual de Londrina}

Chegamos a mais um final de ano com os sentimentos misturados de espanto, cansaço e, quiçá, gratidão. Espanto, por termos passado por um ano tão atípico, trancafiados em nossos próprios lares, convivendo mais do que nunca pelos modos virtuais. Cansaço, o nosso conhecido companheiro, remasterizado pela pandemia deste ano: cansados dos dias iguais, da sobrecarga extra do trabalho remoto, de esperar a vacina. Mas também gratidão: por estarmos vivos (dentre os mais de 170.000 que se foram em nosso país). Mas, sobretudo, por termos sobrevivido ao esvaziamento das relações face-a-face, por termos dado conta do excesso e da falta em um mundo em transição. O natal e o ano novo apontam novamente no horizonte trazendo a esperança cíclica de um ano melhor. Quando - copo está meio cheio, pensamos que a esperança nos faz agarrar na expectativa de que aquilo que está por vir será melhor e, assim, conseguimos seguir em frente. Quando o copo está meio vazio, a recordação que vem é a interpretação de Machado de Assis sobre a caixa de Pandora:

- Porque levo na minha bolsa os bens e os males, e o maior de todos, a esperança, consolação dos homens. Tremes?" (p. 11, domínio público ${ }^{1}$ ).

Diz Pandora a Brás Cubas. O dom do mito é transformado no pior dos males, na leitura do nosso maior autor (constantemente constatado nas frases "o trabalho é ruim, mas sustenta. O amor é pouco, mas a solidão é maior"...). O vazio e o cheio definem, simultaneamente, esse ano? A esperança boa e má, também? Nossa senhora dos Lacanianos nos ajude a suportar! Santo protetor das Kleinianas nos ajudem a transformar!

Divagações à parte, o vazio que nos chamou mais atenção esta semana foi o esvaziamento da Universidade. Que já estava tão esvaziada de recursos, concursos, créditos e propostas, isso já estávamos acostumados. Ah, mas o vazio 
de ver os corredores sem as nossas melhores almas, os alunos, os docentes, esse vazio doeu. O trabalho presencial dos técnicos sem o motivo de estarmos ali nos pareceu sem sentido. E talvez seja. Mas uma coisa é certa, notamos: ela está cheia de baratas! Bem que se disse uma vez que somente elas restariam no fim do mundo, junto com os escorpiões. Esses ainda não nos visitaram.

Com essa reflexão, avisamos que após seis anos de atividades ininterruptas, a editora Dra. Patrícia Silva Lúcio deixará de assinar nossas publicações. Esperamos que esta saída, motivada principalmente pelo excesso de trabalho, não seja um vazio para a revista, que os frutos que passaram pelo programa de formação da revista, alunas de graduação e pós-graduação, encham as produções brasileiras de volumosa qualidade. Que a leitura deste último volume seja tão prazerosa quanto o trabalho que desenvolvemos aqui.

\section{GERÊNCIA DE EDITORAÇÃO}

Dra. Maíra Bonafé Sei, Universidade Estadual de Londrina, Brasil

Dra. Patrícia Silva Lúcio, Universidade Estadual de Londrina, Brasil

\section{CONSELHO EDITORIAL}

Dra. Acácia Aparecida Angeli dos Santos, Universidade São Francisco, Brasil Dra. Alexandra Anache, Universidade Federal de Mato Grosso do Sul, Brasil Dra. Andrea Bustos Ibarra, Pontificia Universidad Católica de Valparaíso, Chile Dra. Evely Boruchovitch, Universidade de Campinas, Brasil

Dr. Manoel Antônio dos Santos, Universidade de São Paulo (Ribeirão Preto), Brasil

Dr. Roberto Calazans, Universidade Federal de São João Del Rey, Brasil

Dr. Sebastián Urquijo, Universidad Nacional de Mar Del Prata, Argentina

\section{COMISSÃO EDITORIAL}

Debrora Klajnman, Universidade Estadual de Londrina

Maria Lúcia Ortolan, Universidade Estadual de Londrina

Nathália Tavares Bellato Spagiari, Universidade Estadual de Londrina

\section{APOIO TÉCNICO}

Ana Carolina Moraes Silva, Universidade Estadual de Londrina Eleonora Sonoda Gomes, Universidade Estadual de Londrina, Brasil

\footnotetext{
${ }^{1}$ http://machado.mec.gov.br/obra-completa-lista/itemlist/category/23-romance
} 